\title{
Moving Towards Nexus Solutions to 'Energy' Problems: An Inclusive Approach
}

\author{
Ralitsa Petrova Hiteva
}

\begin{abstract}
This chapter offers an innovative approach to examining how fuel poverty in one of the most affected countries in the EU: Bulgaria can be examined as part of the urban nexus of food, water, energy and the environment. Building on bodies of literature of the nexus, fuel poverty, energy transitions and energy geographies, this chapter uses the example of energy provisioning in the capital city of Bulgaria: Sofia to illustrate how a more inclusive approach to addressing fuel poverty and air pollution can be developed. The case study unpacks the urban nexus by examining three practices: urban gardening, making zimnina, and heating and energy use in the home. It illustrates how the interdependencies between the practices of urban gardening, making zimnina and domestic heating and energy use have direct implications for the energy system of provisioning and can be important vectors in the energy transition for vulnerable citizens in the city. The chapter addresses an important research gap in urban nexus literature by offering a compelling empirical account of mapping nexus interactions through the perspective of vulnerable users, focusing on lowtechnological ways of managing the urban nexus (rather than technologically driven integration across sectors).
\end{abstract}

\section{Introduction}

This chapter treats energy and energy problems such as fuel poverty as part of a nexus of food, water, energy and the environment. The chapter argues that a more inclusive (future) energy system could be built on recognising and taking into account the diverse and multiple linkages of energy and other systems, unfolding across technologies, practices, users and systems of provisioning. Unpacking the energy system as an element of the urban food-water-energy-environment nexus, this chapter uses the example of energy provisioning in Sofia, Bulgaria to illustrate how a more inclusive approach to addressing fuel poverty and air pollution can be developed. The proposed urban nexus approach is inclusive of vulnerable user experiences,

R. P. Hiteva $(\bowtie)$

Science Policy Research Unit, University of Sussex, Brighton BN1 9SL, UK

e-mail: R.Hiteva@ sussex.ac.uk 
environmental considerations and cross-sector interdependencies. The chapter also proposes a starting point for a new bottom-up institutional approach to addressing fuel poverty and air pollution building on existing practices. In doing so the chapter illustrates the importance and potential powerful impact for the lives of vulnerable energy users of social inclusiveness in transforming the energy system.

The case study discussed in this chapter examines the way energy is provisioned and specifically not consumed (in other words saved or preserved) in Sofia. Because of the case study focus on an urban environment and due to the nexus relationships unfolding in an urban context, the paper refers to the 'urban' nexus. The case study unpacks the urban nexus by examining three practices: urban gardening, making zimnina, and heating and energy use in the home. The chapter addresses an important research gap in urban nexus literature by offering a compelling empirical account of mapping nexus interactions through the perspective of vulnerable users, focusing on low-technological ways of managing the urban nexus (rather than technologically driven integration across sectors).

Fuel poverty in Bulgaria has had limited discussion within the broader EU energy landscape and most discussions have been about the negative impact of fuel poverty and its preconditions (Bouzarovski et al., 2011; Buzar, 2007; Kisyov, 2014; Kulinska, 2017; Lenz \& Grgurev, 2017). There has been very limited discussion about the informal practices of vulnerable energy consumers as a way to address fuel poverty in Sofia and their potential to aid the development of a more inclusive energy system in Bulgaria and more responsive strategies for fuel poverty mitigation (EPOV, 2020). The focus of the discussion on Sofia is illustrative of how the coping practices and fuel poverty conditions discussed are applicable to many countries in Southern and Central Europe, carrying a transformative potential beyond the Sofia case study (Carper \& Staddon, 2009; Bouzarovski et al., 2011; Lenz \& Grgurev, 2017; Petrova \& Prodromidou, 2019).

Despite having both one of the highest levels of fuel poverty and (seasonal) air pollution in the EU, these two problem areas are treated separately and with poor results. Responses to fuel poverty are disjointed and limited because of the underpinning framing of the issue as lack of energy affordability at the point of use. The connection between fuel poverty and clean air needs to be reframed to break the vicious circle of fuel poverty leading to environmental pollution, disproportionately affecting vulnerable people.

Furthermore, at the time of writing, and to the best of the author and editors' knowledge this is the first account and discussion of energy provisioning, air pollution, fuel poverty and energy transitions in Sofia as part of the urban nexus of food, water, energy and the environment. In this respect the chapter offers a uniquely innovative approach building on bodies of literature on the nexus, ecologies of practices, fuel poverty, energy transitions and energy geographies. The chapter will be a suitable resource for undergraduate and postgraduate students; organisations working with and on behalf of vulnerable energy consumers; public policy professionals at local, regional and national level; energy and environmental practitioners; third sector researchers and representatives; and public and private organisations and individuals engaged in the energy transition. 
Data about the urban nexus in Sofia was collected as part of the Resnexus project (2015-2019) funded by the Economic and Social Research Council in the UK (Ref: ES/N011414/1) to investigate the interdependencies between food, water, energy and the environment (the "urban nexus"). The data was collected between June and September 2017, and January and March 2018, and involved 42 observations, 54 interviews, 2 focus groups and 12 questionnaires. In some cases, this involved multiple observations during the summer (main urban gardening and zimnina-making period) and the winter months (zimnina consumption and heating and increased energy use in the home period).

This chapter proceeds by outlining the conceptual and empirical background of fuel poverty in the case study location, Sofia, introducing the concept of the nexus and the fuel poverty-air pollution nexus in the city (in Section "The Conceptual and Empirical Context of Fuel Poverty in Sofia"). Section "Systems of Provisioning and User Practices: Urban Gardening, Making Zimnina and Domestic Heating" outlines a nexus understanding of the systems of provisioning through the practices of urban gardening, making zimnina, and domestic heating and energy use. Section "Understanding the Fuel Poverty-Air Pollution Nexus in Sofia" situates the fuel poverty-air pollution nexus in Sofia within the urban nexus of the three practices. Section "Framing Inclusive Nexus Solutions for Inclusive Energy Transitions: Reflections and Conclusions" offers reflections and conclusions on how understanding of the urban nexus can underpin the development of an inclusive energy transition.

\section{The Conceptual and Empirical Context of Fuel Poverty in Sofia}

This section aims to unpack the multiple dimensions of fuel poverty as a geographic socio-technical concept and illustrate the scope, nature and extent of fuel poverty in Sofia. Building on these two areas of understanding this section then introduces the fuel poverty-air pollution nexus in Sofia.

\section{Understanding Fuel Poverty_Useful Conceptual Frameworks}

Fuel poverty and energy poverty are often used interchangeably although having slightly different meanings. Fuel poverty is commonly described in terms of affordability. One of the most used definitions describes households, persons or families spending more than twice the median on fuel, light and power. Frequently used measurements of fuel poverty include households that spend greater than 10 or $15 \%$ of their monthly income on energy services (such as heating or cooling); or households that actually spend more on energy than on food (Tirado Herrero \& Urge-Vorsatz, 
2012). "Severe fuel poverty" indicates spending 15-20\% of household incomes on energy, i.e. between three- and four-times the median for a given year; "extreme fuel poverty," spending above $20 \%$ or greater than four times the median for a given year (Liddell et al., 2012).

Conceptions of fuel poverty have been heavily influenced by Boardman (1991, 2010) who initially argued that "fuel poverty occurs when a family is unable to afford adequate warmth because they live in an energy-inefficient home" (Boardman, 1993). Boardman argued that fuel poverty occurs when a household is unable to afford adequate energy services in their home on their present income, highlighting the importance of "consistent, defined standards of energy services, not just actual expenditure" (Boardman, 2012). O'Brien (2011) points out that fuel poverty is conditioned by household income as much as fuel prices and the energy efficiency of residential building stock.

People with incomes above the accepted poverty line may also not be able to afford to be warm, because their home is difficult or expensive to heat. Some energy services, such as heat, can only be purchased at the expense of adequate diets or going short in other ways (less frequent showers, socialising, buying medicine, etc.). Others with incomes sufficient to purchase adequate energy services may still live in cold conditions because of helplessness or fear of fuel bills (Bradshaw \& Hutton, 1983). Poor quality of housing in terms of thermal efficiency, high levels of income inequality, and rapid increases in the real price of residential electricity lead to problems of affordability (Howden-Chapman et al., 2012). The link between all three is such that "raising incomes can lift a household out of poverty, but rarely out of fuel poverty" (Howden-Chapman et al., 2012).

Because of the impact fuel poverty has on meeting other everyday needs, the EU's definition includes households "whose resources (material, cultural and social) are so limited as to exclude them from the minimum acceptable way of life in the Member State to which they belong" (Moore, 2012). An inadequate supply of energy often means an inadequate supply for other basic domestic needs such as for food storage and cooking, maintenance of personal and domestic hygiene, and artificial lighting. Fuel poverty is a multi-dimensional phenomenon which depends as much on who it affects as where it takes place. It encompasses a wide variety of sociodemographic, institutional and built environments that render some households more vulnerable by virtue of their demographic circumstances, housing conditions and relationship to the state (Petrova \& Prodromidou, 2019). Such findings point to the need to look beyond the triad of energy prices, incomes and energy efficiency within which energy poverty has been traditionally conceptualized (Bouzarovski, 2014; Petrova et al., 2013). Understanding of the concept is further expanded by the innovative work of Petrova and Prodromidou (2019), who enable drawing of key similarities between Greece and Sofia (Bulgaria) ${ }^{1}$ and mobilise a more nuanced

\footnotetext{
${ }^{1}$ Fuel poverty in Bulgaria is often discussed alongside other South Eastern countries like Greece and Romania, because of the big similarities (social, economic and technical) between them.
} 
understanding of fuel poverty in relation to the urban nexus, ${ }^{2}$ by unpacking the complex social and spatial patterns that influence the emergence of fuel poverty.

Petrova and Prodromidou (2019) broaden the discussion of fuel poverty vulnerability by discussing the "new energy poor" in neighbouring Greece. A new category of fuel poverty which "cuts across traditional class boundaries, by including people of different genders and ages, as well as diverse ethnic and educational background" which, they argue, has emerged as a result of austerity measures and existing problems, "such as thinly insulated and inadequately heated homes, and built, institutional or ownership arrangements that do not allow households to improve the efficiency of the housing stock or switch towards more affordable fuels (Katsoulakos, 2011; Santamouris et al., 2014)". The "new energy poor' ${ }^{3}$ struggle to secure adequate domestic energy services due to the economic crisis and austerity regime, as well as path-dependent infrastructural and policy settings, across a variety of urban and peri-urban sites.

Petrova and Prodromidou (2019) also argue that "linking the intimate geographies of households (Valentine, 2008) with ...geographies of people's dealings with austerity" can inspire the development of wider progressive politics (Jupp, 2016), calling for research on the links between energy, environmentality and austerity (Alejos $\&$ Paz, 2013), especially in the context of residential energy use. This progressive research and policy agenda also builds a more critical and in-depth investigation of how these relationships unfold beyond cities, and include integrative thinking about rural and suburban areas. Roy (2005) highlights the importance of the urban-rural interface as a key space for dynamic energy experimentation.

By unpacking the fuel poverty as part of the urban nexus this chapter also unfolds the ways in which the urban nexus is affecting the everyday rhythms and synchronicities of residential energy use (Walker, 2014), creating new temporal patterns embedded in the social world. Greater recognition of these patterns and the ways in which there are disrupted are urgently needed, as 'sustainable energy transitions and pathways ... are mediated by unique place and context-specific conditions that exert influence on the mobilisation of resources, governance capabilities and actor-networks' (De Laurentis et al., 2016). Thus, holding a promise of identifying innovative and powerful ways for sustainable institutional change, towards a more inclusive energy transition.

\section{Empirical Context of Fuel Poverty in Bulgaria}

Fuel poverty in Bulgaria in general and in the capital city of Sofia, in particular, is an issue of key concern at the national and EU level. Compared to an average of $8 \%$ for the EU and $16 \%$ for the region, $39.2 \%$ of the Bulgarian population was unable to keep their homes warm in 2016. These figures continue to be the highest in the

\footnotetext{
${ }^{2}$ The concept of the urban nexus is defined in Section "Understanding the Nexus".

${ }^{3}$ The concept was first developed by Kaika (2012).
} 
EU (Eurostat, 2020). It is believed that the real numbers of fuel poverty are much higher and could be over $50 \%$. Thus, those living in fuel poverty are not only people belonging to traditionally vulnerable groups such as the elderly, disabled and those in long term unemployment, but include households in full time employment, or what Petrova and Prodromidou (2019) call the "new energy poor". Although, Bulgaria has not experienced the acute levels of austerity which took place in Greece over the past 5 years, the group of fuel poor and vulnerable continues to grow, albeit slowly.

\section{Technology Issues: Inefficiencies and Lock-In}

Fuel poverty in Sofia has strong links with a specific technology, district heating (DH) and the extent to which it is embedded in the built environment for many users. Although DH is not the only reason for the high number of people in fuel poverty, it disproportionately affects vulnerable households living in apartment type dwellings (EPOV, 2020). DH is the main form of heating and hot water supply in densely populated cities in Bulgaria, serving $26.5 \%$ of the Bulgarian population. About $65 \%$ of the national heat supply is produced by combined heat and power (CHP) plants in Sofia. However, DH suffers from strong path-dependency and lock-in: the DH sector was built during the 1950s and 1960s and was designed to provide a collective, subsidized heat supply without consideration for individual consumer needs. During this period the supply of raw resources was also strongly subsidized by the Bulgarian state and the former Soviet Union and heat was provided at a fixed price below the cost of production.

The DH system was poorly designed from the start and it was highly inefficient at the point of installation and did not allow reduction of supply costs. Furthermore, insufficient maintenance and investments led to gradual deterioration of the $\mathrm{DH}$ assets, low efficiency of operations, and poor quality of services. Large-scale disconnection of households from DH services (over 30\%) took place between 1994 and 2000, and continues today. The decreasing customer base, with low collection rates (due to non-payments and heat and power thefts), the use of low-grade coal (lignite), growing popularity of and funding for energy efficiency retrofits, and poor energy governance in Bulgaria further weakened the financial condition of the DH company. These conditions play out particularly badly for customers living in apartment type panel buildings. In Sofia central heating (mainly DH) is used by around $11 \%$ of households and over $20 \%$ of the buildings are panel buildings, most of them needing renewal $(680,000$ buildings needed renewal by 2020), half of which were panel buildings. 


\section{Cost, Access and Billing}

The increase in fuel (mainly gas and oil) prices toward world-market levels in the mid1990s (following the collapse of favorable trading relations with the former Soviet Union) heavily impacted the cost of heat production and put the state budget under financial pressure. Because of these structural issues DH has long been one of the most expensive ways of providing heat and hot water in Sofia. Despite privatization and modernization changes since the early 1990s, problems with billing, with many customers being routinely overcharged and customers not having access to their heat or hot water meters persist. For example, household heat and hot water meters are locked behind specially designed cabinets to prevent tampering, with company representatives having the only keys.

DH heating bills are calculated on the basis of consumption in the same month of the previous year, which is adjusted by a fixed rate. Unseasonal cold weather in a previous year for example could impact bills a year later. Such jumps in bills are also compounded by yearly hikes in the price of heating. For example, the price of heating jumped by $23 \%$ in April 2018 compared to the previous year. The actual energy consumed by customers during the heating season becomes clear after the heat meters are read and balancing bills are issued. This means that many are faced with what is often referred to as "impossibly high bills" when the cold weather ends and people are using less heat on a daily basis. The complexity of heating bills and the fact that customers rarely have access to their heat and hot water meters leads to high levels of distrust among consumers. The impact is even bigger on vulnerable customers who feel any increases in the price more acutely. Ultimately, heating bills are a worry for many even beyond the heating season (October to March).

The DH company in Sofia is owned by the local municipality and is a monopoly. With the DH company in the red for over 2 decades, the price of heat increases on a yearly basis, while the company reports losses of over $20 \%$ due to poor infrastructure and theft of heat and hot water. The theft of heat and hot water is a widely spread practice in Sofia and can involve tampering with meters and radiators in individual properties (flats). The DH company measures the supplied amount of heat and hot water to the whole building, meaning that thefts inevitably mean higher cost for all other customers in the building. This means that ultimately, individual households do not have full control over their energy (heat and hot water) bill, something which affects many of their practices all year around. Often, the only way to exercise control over heat and hot water bills is by switching radiators off, using cold water and having greater control over how electricity is supplied in the household. The latter often involves the use of alternative technologies such as gas heaters and hobs, and wood burning stoves. 


\section{Still a Price to Pay Even if Disconnected}

Many customers, particularly vulnerable customers wish to disconnect from DH altogether but are unable to if they live in multifamily buildings. Even if radiators are removed from individual properties they are still eligible for an amount to cover heat transference from pipes which run through the walls and through communal spaces, such as corridors and hallways.

Although retail electricity prices in Bulgaria are the lowest amongst countries in the EU (price per kWh), the high levels of fuel poverty and low levels of ability to keep adequately warm are multiple, systemic (connected to the historic way electricity and heat are provisioned in Sofia) and personal (linked to low earnings and old housing infrastructure). Another key issue is the low levels of energy efficiency performance in homes, with multi-family buildings being particularly hard to retrofit (Kulinska, 2017; Tirado Herrero \& Urge-Vorsatz, 2012).

There are multiple barriers to overcoming fuel poverty, starting with low quality of life, unhealthy living conditions and inability to maintain the building stock. Many vulnerable citizens meet only their most pressing heating needs, using wood and coal, sometimes illegally traded. Government support is focused on subsidizing final energy consumption, which often increases energy consumption, rather than examining the coping practices of vulnerable users and the non-energy/indirect ways in which they seek to control their energy use.

\section{Understanding the Nexus}

'Nexus' is often used to denote two or several interlinked issues, systems, subjects etc. Although the word nexus means "to connect" (De Laurentiis et al., 2016), in the way it is used here it also refers to the interactions (inter/dependencies) between two or more elements, including the synergies, conflicts and trade-offs that arise from how they are managed. Multiple definitions and meanings of the nexus exist, some of which are overlapping (Al-Saidi \& Elagib, 2017), however they all tend to have a "strong normative resonance" (Cairns \& Krzywoszynska, 2016) towards better, more efficient and/or sustainable management of resources. Although different variations of the nexus exist_energy-water-food (EWF) nexus; food-energy-water (FEW) nexus; water-energy-food (WEF) nexus - the nexus approach is multi-centric. De Loe and Patterson (2017) suggest that what is paramount is "nexus thinking," as opposed to a specific strict definition of the nexus.

Recent nexus thinking has argued for the inclusion of climate change and the environment (Allouche et al., 2015; Pahl-Wostl, 2017) when considering the nexus. Wichelns (2017) argues that much of the interest in the nexus is a result of the concern of the impact of climate change on water, energy and food security, as all three resource sectors are influenced by climate change and that they, in turn, each contribute their own emissions (Rasul \& Sharma, 2015). Most responses to the arising complexity from a nexus approach are addressed through modelling the nexus (i.e., 
computer-based modelling) (Daher et al., 2017). However, localising and contextualising the nexus is key to addressing its trade-offs (Daher et al., 2017; Simpson \& Jewitt, 2019) and preparing an adequate policy response. Overall, since the increased interest in understanding the nexus, approaches which focus on mapping nexus interactions through the perspective of users, and vulnerable users in particular, have been few and far between.

In Sofia, as in many other cities around the world, local inequality is materialised as vast disparity, between groups of people, in terms of access to nutritious food, clean water and energy. Resilience then points not just to a capacity for adapting to the impacts of climate change and other forms of unsustainability, but also to the transformation of extant socio-ecological systems of provision towards producing social equality and ecological integrity. To begin with, such transformations require the recognition of complex interdependencies between the environment and the practices of food, water and energy production, distribution and consumption, as well as of the connection between the practices. Rather than promoting technical solutions based on data integration from the different sectors, a transformative nexus approach seeks to build on the experiences and practices of different communities, some of which are marginalised and vulnerable.

The food-water-energy-environment nexus emerges from interacting social and physical systems (de Grenade et al., 2016), in the case study of Sofia meaning practices and systems of water, energy and food provisioning, and the environment. The interdependencies between these heterogenous elements of the nexus are as much about how social and ecological systems relate to each other, as it is about the material way in which social and ecological systems are interconnected (Williams et al., 2018). Thinking in terms of a nexus means allowing for, taking into consideration and creating new interconnections across different political scales (individual practices, cities and national level policy) and between nature and people.

The fuel poverty-air pollution nexus in Sofia can be understood in the context of the wider urban nexus of food, water, energy and the environment. This would entail not focusing purely on the inter/dependencies of fuel poverty and air pollution, but embedding them (i.e. localising and contextualising them) in the relationships between three interrelated practices: urban gardening, making zimnina, and heating and energy use in the home. These three user practices are discussed in turn in Section "Systems of Provisioning and User Practices: Urban Gardening, Making Zimnina and Domestic Heating".

Understanding practices of energy use through the nexus is inclusive of the experiences of some of the most vulnerable practitioners, and of scales of analysis at the local, community and household levels, which are understudied in environmental management and nexus literature. Nexus analyses are often conducted at regional or national levels (due to the availability of data or national-level policy goals or metrics) (Miralles-Wilhelm, 2016) with smaller, more localised scales missing in most nexus discussions (Prasad et al., 2012). Common nexus approaches tend to focus on integration between systems, often through technological innovation such as smart technologies, side lining or failing to engage with low tech solutions and 
practices. This chapter's focus on socio-technical and ecological interconnections can also be thought of as inclusive of the agency of ecological processes, such as climate change.

\section{Understanding the Fuel Poverty-Air Pollution Nexus in Sofia}

Fuel poverty and air pollution in Sofia are tightly interlinked, and their interdependencies are at the heart of the urban nexus. The nature of these interdependencies is unpacked in this section.

Sofia is one of several most polluted European cities in South-Eastern Europe. The air pollution with particulate matter is to a large extent due to the use of wood and coal as a source of residential heating, and a direct result of the low purchasing power of the population. The multidimensional nature of the link between fuel poverty and air quality is yet to be unpacked and incorporated in current policies and measures. Fuel poverty and poor air quality are long-standing issues in the EU, but are yet to gain EU-wide recognition. As a result, policies for energy, environment and climate issues are rarely integrated (InventAir, 2018).

An Energy Agency Plovdiv (EAP) study (in InventAir, 2018) on the link between fuel poverty and air pollution in Sofia shows that households using wood and coal for heating live in worse housing conditions than the rest of the population. Their homes are usually brick-based, single-family, with a local heating boiler $(58 \%)$ or without any heating infrastructure $(35 \%) .57 \%$ of the homes do not have any insulation and $55 \%$ of the households use additional electrical devices for heating, and an electric boiler for domestic hot water $(30 \%)$. Around $60 \%$ report monthly income per household member around 250 EUR and another $60 \%$ report monthly energy bill above 250 EUR. Eurostat reports that between 32 and $47 \%$ of the roundwood production in Bulgaria is fuelwood, and its use in old and inefficient stoves is a major contributor to air pollution in the winter (InventAir, 2018).

Air quality in Bulgaria has been decreasing for several years, with great implications for public health. There are regular recordings of concentrations of PM2.5 and PM10, which are much higher than the limits set by the EU and the World Health Organization to protect citizens' health. These concentrations affect up to $92 \%$ of the population, resulting in the highest rate of premature deaths due to air pollution in the EU (217 deaths per 100,000). This health crisis is attributed to household and ambient air pollution, and it is particularly bad in Sofia. Although this means that Bulgaria is in almost constant breach of EU air quality laws and was ordered by the EU Court of Justice in 2017 to take action to improve its air, little has been done. The office of the Mayor of Sofia has denied that poor air quality is an issue on multiple occasions (HEAL, 2018). This points to an institutional blindness and lack of willingness to act on the interconnections between fuel poverty and air pollution in the city. Rather than obscured and visible only to those who are vulnerable, the fuel poverty-air pollution nexus in Sofia is highly visible. 
Like Bulgaria, Greece has seen a significant increase in air pollution, over the past 10 years (a 30\% increase in the mass concentration of PM 2.5 particles and a up to five-fold increase in the concentration of wood smoke tracers) within large urban areas mostly due to the increased use of fuelwood for residential space heating (Saffari et al., 2013). This leads to situations where in the winter months big cities like Athens (in Greece) and Sofia (Bulgaria) are covered in smog for days (Petrova \& Prodromidou, 2019; Hiteva, 2017).

In recent years, there has been strong political and financial support for renovating the outdated residential building stock, even in harder-to reach multifamily residential buildings. However, even in retrofitted properties, often people chose to disconnect from DH networks and turn to wood and coal heating. Low-income households using old inefficient heating equipment and/or poor-quality heating fuels are not the only ones to blame for dramatic seasonal increases in air pollution in Sofia. Vulnerable households are often disadvantaged not only by high fuel prices, poor infrastructure and often less flexibility in shifting their energy demand. They tend to have more limited information about energy use and options, as well as pollution levels and related health impacts. Social welfare systems often do not provide enough support regarding trade-offs between different domestic heating and energy systems (Hajdinjak and Asenova, 2019).

Because of the high levels of fuel poverty and seasonal vulnerability many households experience systemic issues with DH in the capital (around lack of transparency and billing) and rely on multiple energy resources, often including gas, electricity, DH and wood to meet their energy needs. Wood burning stoves coexist with electric radiators, central heating and air-conditioning. Sometimes in the same room. Often each room in a home will have an independent and different way of providing the necessary energy services. People in Sofia go to great lengths to make sure that they have control over where the heat comes from, how much they use and at what cost. This means that the links between fuel poverty and air pollution are deeply embedded and complex.

The fuel poverty-air pollution nexus is produced by the intersection and interdependencies between the often poor energy performance of the housing stock for many households (due to lack of adequate insulation; quality of building materials, poor maintenance etc.); the use of old, inefficient and poorly maintained heating systems; the use of low-quality fuel (wood, coal and briquettes; e.g. with high humidity or sulfur content) or even waste burning; and the high levels of fuel poverty and seasonal vulnerability in Sofia. Residential burning of low-quality fuel, often by inefficient heating systems, in poorly performing dwellings leads to substantial emissions of short-lived climate pollutants (SLCPs). Black carbon, for example, is part of particulate matter and is a particularly big contributor to global warming. Black carbon is one of the air pollutants which is commonly found in Sofia during the winter season. The reduction of particulate matter and nitric oxide pollution during the winter season is directly proportional to the reduction of the combustion of solid fuels (wood and coal) for domestic heating.

The increased use of fuelwood, according to Knight (2014), is because every crisis embeds memories of previous difficult periods, and the solutions to current problems 
usually involve techniques and practices used in the past. Wood-burning stoves are a traditional technology in Bulgaria for heat and cooking services, and many currently residing in urban environments like Sofia have access to such stoves in ancestral homes in rural areas. In many cases, as in Greece, the return of this 'archaic' system of space heating to urban areas can be accompanied by the reliance on more modern appliances such as air conditioners (Petrova \& Prodromidou, 2019).

Limiting the harmful effects of domestic heating depends to a large extent on the successful implementation of energy policy, and although NGOs like EAP and EnEffect emphasize the importance of energy efficiency measures in buildings (HEAL, 2018), the role of user experiences and practices of energy use as part of interconnected systems of food-water-energy-environment has not been investigated. Existing energy efficiency programmes and schemes for alleviating fuel poverty often end up giving out grants to vulnerable households, who spend the money on purchasing low quality and inefficient fuels (like wood) and stoves (InventAir, 2018), inadvertently leading to nexus aggravations. This dominant approach to fuel poverty alleviation and the institutional blindness to the urban nexus relationships necessitates a new way of 'seeing' and addressing the fuel poverty- air pollution nexus in Sofia.

\section{Systems of Provisioning and User Practices: Urban Gardening, Making Zimnina and Domestic Heating}

In the case of Sofia, the nexus of food-water-energy-environment was studied through the interdependencies between the practices of urban gardening, making zimnina (food preparation for the winter) and domestic heating and energy use.

For the purposes of the study urban gardening is defined as comprising all activities related to the growing of food within and near the city (from inner city allotments and community gardens to peri-urban off-ground cultivation) or that have a functional relationship to it (for example, if any elements of the practice of urban gardening depend on a flow of resources and materials through the city). This could include cultivation in a wide range of urban spaces including windowsills, rooftops, balconies, building corridors, gardens, backyards, urban/peri-urban/rural allotments, spaces between blocks of apartments and alleyways. Urban gardening in Sofia tends to be small in size (practiced usually by individuals and households); and includes a wide range of informal activities, carried out primarily for self-consumption, and is driven by desire for self-sufficiency.

Urban gardening is an informal practice and involves a large number of people, of different ages and social status in Sofia. While some practice urban gardening for recreational purposes and as a way to get exercise, fresh air and produce their own food, for the majority of urban gardeners encountered, urban gardening is the means of getting fresh food for most of the year. This includes not only traditionally vulnerable groups - such as those on low-incomes, full time carers or disabled-but 
also people who are employed and who experience seasonal vulnerability such as fuel poverty. For some vulnerable participants, urban gardening is the only means to get fresh fruit and vegetables for most of the year.

Practices of urban gardening are closely interlinked with practices of making zimnina. Zimnina is a broad category which includes any food prepared and preserved for consumption in the winter months. This often involves the preservation of cooked food through canning using glass jars and metal tops. Making zimnina is very energy and water intensive, and often a complex endeavour, involving a multitude of transformations (boiling, frying, steaming, heating) and spaces (gardens, windowsills, balconies, spaces between and in front of blocks of flats, pavements and building hallways). Making zimnina in the city often necessitates the use of different types of energy. Most often these include a combination of gas, electricity and wood.

Making zimnina can be more labour, energy and water intensive for vulnerable groups (e.g., pensioners, single parents, low-income families, unemployed and disabled people) as they tend to wash, sterilize and cook the jars and produce at a high temperature to ensure that the zimnina lasts until the end of the winter (often more than 6 months). Many urban gardeners who are vulnerable to fuel poverty make use of collected wood and burn what is generally considered garbage (old clothes, plastic tubs and bottles) when preparing the zimnina (usually this takes place between May and September).

The interdependencies between the practices of urban gardening and making zimnina are particularly prominent for vulnerable practitioners. Making zimnina is an important way to redistribute food through the winter. Those suffering from fuel poverty will often survive through the winter months by eating and cooking zimnina which they make during the summer and autumn from produce they grow in their gardens. In fact, the only way many vulnerable people are able to make zimnina is if they are also able to grow their own fruits and vegetables. These interdependencies are illustrated by the experiences of one of the vulnerable participants in the study, Maria. $^{4}$

Maria is a pensioner living 10 min away from Sofia's city centre. She has been making zimnina all her life. She starts preserving food for the winter as early as June. So, she peels, boils, fries, stuffs and closes jars with fruits and vegetables almost every day until the end of September to make enough food to last her until April next year. Experience has taught her to do this in a meticulous way: cleaning all the vegetables, fruits, glass jars and metal tops really well with plenty of water. Frying everything long enough and boiling the stuffed jars at a high enough temperature so that they last up to 6 months. She makes 1 litre jars of mixed vegetables, seasoning and cloves of garlic, which can be eaten cold, as a salad and warmed up on the wood burner in the room where she cooks, sleeps, washes herself and spends her days during the winter. Her practice is driven by the need to provide a full meal or even multiple meals for the day for herself, thus buying only bare necessities during the winter: "medicine, bread, soap". Everything else goes to bills, with heating and electricity being the biggest one. For Maria making zimnina is an important way to redistribute

\footnotetext{
${ }^{4}$ Maria's real name has been changed to protect her identity.
} 
food through the winter, impossible without growing her own fruits and vegetables to do so.

Maria's experience is very similar to that of Anna, ${ }^{5}$ another vulnerable practitioner of urban gardening and zimnina making in the study.

I prepare the jars so that when I open one up it can last me the whole day. I put in everything, the seasoning, the salt, the vinegar, everything really, when I am stuffing the jars, so that I don't need to add anything else later...one half litre jar is enough for breakfast, lunch, and dinner. Sometimes I even have it as a snack...if it's really nice.... That way I don't need to switch the fridge on...If there is anything left I take it outside on the terrace where it's cold. ... That's what I do in the winter. Otherwise I can't manage the heating bills. (Anna, 78-year-old pensioner, 2018)

As illustrated by Maria and Anna's cases urban gardening and making zimnina are closely interlinked with energy use in the household, and domestic heating in particular, the third practice of provisioning analysed here.

Energy provisioning in Sofia lacks the seamlessness that one can expect in cities. Multiple and overlapping ways of provisioning heat is a common place. Wood burning stoves coexist with electric radiators, central heating and air-conditioning, sometimes in the same room. This complexity of energy provisioning is not limited to heat, but also characterizes other energy practices. Households often have a portable gas hob, an electric hob and an oven, as well as access to a wood stove, usually in a property outside of the city. Practices of household heating and energy use in Sofia can include the burning of clothes, waste and low-quality fuels for the most vulnerable. Cooking in the summer is almost predominantly on a gas hob, while in the winter on an electric hob "to warm up the room". In the winter, another participant in the study, Lili $^{6}$ cooks at least three times a day as a way to keep bodies and the flat warmer, the practice of cooking and heating merging together in the winter. In comparison, in the summer, Lili usually cooks only once a day, getting up early in the morning when the air is still cool.

As the cases of Maria and Anna discussed above show, the way zimnina is prepared is closely linked to the use or saving of energy at the point of consumption. Vulnerable people often prepare zimnina in a way which does not necessitate cooking, heating up or refrigeration. What energy and how much energy will be available and used for the making of zimnina and its consumption can shape practices of urban gardening (what to grow, when to plant and when to pick produce); and how zimnina is prepared, stored and consumed. Therefore, we can think of the practices of urban gardening and making zimnina as means for resource (including energy) redistribution between the seasons. Many, particularly vulnerable people, in Sofia are managing the affordability and access to the energy services that they need (i.e. fuel poverty) through the practices of urban gardening and making zimnina. For many, coping with the energy and heating bills is a process which spreads over most of the year.

\footnotetext{
${ }^{5}$ Anna's real name has been changed to protect her identity.

${ }^{6}$ Lili's real name has been changed to protect her identity.
} 


\section{Understanding the Fuel Poverty-Air Pollution Nexus in Sofia}

The practices of making zimnina, urban gardening and domestic heating in Sofia shape the interdependencies between fuel poverty and air pollution in the city. Gardeners making zimnina on a daily basis in the summer often use their allotments, gardens and forage in nearby parks and green spaces for wood, leaves, grass and any other discarded items to feed into the open fires needed to sterilize jars and close them so that they can last during the winter months (Fig. 1). In the summer the process of making zimnina can often be the source of air pollution in outside spaces, as makeshift metal stoves and fires are set up close to multifamily apartment buildings, parking lots, and even on the pavements and in building entrances (Fig. 1). In the winter months, many resort to the same practices of wood and discarded items gathering to feed wood burners set up in houses and apartment buildings, collecting from the same places they use in the summer for zimnina making. Many of the most vulnerable would scavenge the urban landscape collecting items left near and inside communal bins to top up wood specifically purchased for heating in the winter. Those who live in apartments and lack storage space, often use their gardens to store some of the collected materials for burning, regularly returning to their gardens in the winter months to ferry them to their homes.

At the peak of seasonal vulnerability, the trade-offs and choices faced by those in vulnerability for meeting their heating needs are driven as much by the things that are traditionally associated with fuel poverty (i.e. the price of energy, the energy performance of the building stock, etc.), as by their access to 'coping' practices. Coping practices such as making zimnina and urban gardening can help vulnerable

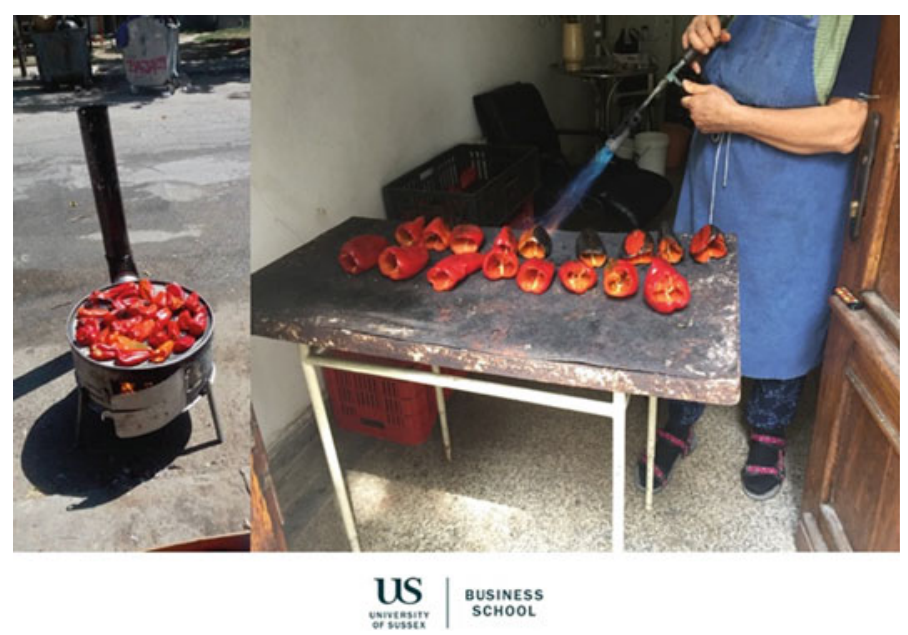

Fig. 1 Photographs of zimnina preparation (1) in the open in the street in Sofia and (2) at the entrance of multifamily apartment building at the centre of Sofia, taken September, 2017 
consumers to manage affordability and access to heating services in the household. For many of the study's participants, access to land and means to practice urban gardening and making zimnina is a way to manage access to and affordability of heating in a way which allows them to practice 'healthier' energy use in the home, i.e. keeping DH radiators on, using wood burners in one room only and using biofuel central heating in houses, rather than lower grade fuels and materials. Households with larger gardens in the outskirts of the city tend to have biofuel boilers which they feed with pellets purchased specifically, mixed with leftovers from the garden and things that they are growing. The ability to synchronize the three practices of urban gardening, making zimnina, and energy use and heating through different parts of the year, in order to manage food, water and energy resources shapes the way environmental resources such as clean air and gas emissions in the atmosphere are managed at an individual and household level. This is illustrated by Hristo ${ }^{7}$ 's words (a 57 years old taxi driver):

It is a complicated system that has taken me years to work out. It is now well-polished and will be hard to replace... It is important to prepare early and to know what to do and when. I start collecting wood as early as May. A little bit here and there during the week, if I see some lying around I take it and put it in the car. I also collect at least a bag of branches every weekend in the park....it is just a minute or so away from the house so it is not hard to carry. Same with zimnina. A jar here or there every other day with things we find. Cheap plums at the market. The other day I saw a kilo or so of tomatoes that were going to be thrown out by the market seller and made it with green beans that I had growing on the terrace. Just a few handfuls, but when you add a clove of garlic and some herbs, it does just the job. Sometimes when we don't have a lot in the cupboard in the winter, we put a few potatoes on top of the wood burner to boil... it takes a bit longer but it does the job..., and add the tomatoes and green beans and mix it all up. If you throw in a bit of pickled cabbage that we make every year, that's me and the wife sorted for the day. It is tasty and we manage.

Although a few of Hristo's neighbours and friends are topping up their wood supplies by burning old clothes and plastics, Hristo has an asthma and is reluctant to do so. He is aware of the air pollution this causes but explains his next door neighbour's practices in terms of urban gardening and zimnina: “... they are struggling more than we are because they are not planning ahead and not everyone can grow things as we do, either because they don't have space to do so or they don't know how. Our neighbours on the right, nice people.... hard working couple... but he has a mobility problem and can't bend down and turn the soil and she works all hours as a cleaner. They can't go and work the land as well. They do make zimnina but mostly from things that they buy on the market and that is expensive. Too expensive. We couldn't do it. ... But they have to survive and they do what they can."

\footnotetext{
${ }^{7}$ Hristo's real name has been changed to protect his identity.
} 


\section{Framing Inclusive Nexus Solutions for Inclusive Energy Transitions: Reflections and Conclusions}

The interdependencies between the practices of urban gardening, making zimnina and domestic heating and energy use have direct implications for the energy system of provisioning and can be important vectors in the energy transition for vulnerable citizens in the city. Including provisions for and addressing these interdependencies in policies, plans and incentives would give recognition and agency to vulnerable users to participate in urban energy transitions. Such an approach recognises vulnerable groups and practitioners as experts in their own practices. Understanding fuel poverty as part and parcel of the urban nexus of food, water, energy and the environment, allows examining the ways in which vulnerable people cope with it by managing resources over time (throughout the year) in an inclusive way, in terms of their experiences, knowledge and practices. This is in stark contrast with purely top-down approaches which seek to increase efficiencies via the use of smart technologies and integration across different systems of provisioning of the urban nexus through data platforms. The approach also opens up opportunities for more innovative and radical ways of addressing issues of fuel poverty.

Seeking only energy solutions to energy problems has some limitations. They limit possible solutions to energy actors, technologies and practices, and preclude any trade-offs possible within the urban nexus of food, water and energy. The nexus approach articulated here provides a detailed picture of interdependencies and the broader contexts within which fuel poverty interacts with the provision of food, water and its impact of the environment. In summary, the way zimnina is made and prepared is shaped and shapes energy access and use, and can affect how urban gardening is practiced. Energy use and energy saving dictates decisions about urban gardening and making zimnina, from the point of seeding to the point of consumption. The way zimnina is prepared is also closely linked to the use (or not use) of energy at the point of consumption. Vulnerable people do prepare zimnina in a way which does not necessitate to be cooked, heated up or refrigerated.

This approach will also offer a better understanding of the multiple and complex ways in which interdependence can lead to nexus aggravations. Making zimnina can be more energy and water intensive for vulnerable groups as they tend to wash, sterilize and cook the jars and produce at a high temperature to ensure that the zimnina lasts until the end of the winter. What energy and how much energy will be available and used for the making or zimnina and its consumption can shape practices of urban gardening (what to grow and when to plant); and how zimnina is prepared, stored and consumed. Interconnected practices of urban gardening and making zimnina can help stop practices of reverting to more air polluting heat provisioning in cities, such as burning of low-grade fuels, wood, plastics, old clothes and etc. With many other countries in South and Eastern Europe having traditional practices of zimnina making and climbing rates of fuel poverty, it is likely that the nexus interdependencies work in similar ways, making learning from the case of Sofia imperative beyond the country's borders. 
The call for institutional change in addressing fuel poverty and designing placebased responses to environmental problems such as air pollution in cities is also clear. Rather than policies focused on the cost of energy over a limited and rigid amount of time, local and national authorities can use nexus thinking to map and understand the multiple ways in which the provisioning of food, water, energy and the environment break administrative and policy silos, and point to mobilisation of resources, governance capabilities and actor-networks towards more inclusive energy transitions. For a start, community discussions of energy transitions and fuel poverty in the urban environment, in cities like Sofia, should involve individuals, communities and in/formal networks involved in urban gardening, whose expertise and experience are part of inclusive strategies for supporting those living in fuel poverty. Such an inclusive and bottom-up approach would reframe vulnerable consumers as experts in resource distribution, rather than struggling to manage the resources at their disposal.

Advocating for support of practices that can be interpreted as enabling the reproduction of fuel poverty may feel counter-intuitive. However, fuel poverty in Bulgaria is so long-standing that it is 'normalised' (i.e. accepted by both people and institutions). The level of its embeddedness also indicates that existing energy-based and top-down financial solutions have failed to significantly reduce the number of people affected by it. Thinking of the urban nexus as a means of energy control and redistribution opens up opportunities for identifying means for self-management for vulnerable people and using them to support them. Learning from widespread bottom-up and informal practices can guide policy towards more inclusive and sustainable energy transitions in Sofia.

Supporting the practice of urban gardening would aid other related practices such as making zimnina, heating and using less energy and less polluting energy in the home. A nexus intervention aiming to alleviate fuel poverty in Sofia could involve providing support for urban gardening and making zimnina, which could range from access to land suitable for urban gardening in the city to tools and access to water and zimnina making facilities, rather than just money to cover the cost of energy, which ultimately goes to energy companies (the current approach). This would mean that fuel poverty support will not only take place during the winter months but for most of the year (as urban gardening can take place from March until November, and gardens in Sofia can produce vegetables such as broccoli and spinach even during the winter months). This means that charging rent or a fee for land use for the purposes of urban gardening (at a communal or individual basis) will rob those who are most vulnerable of an important coping mechanism against fuel poverty. However, connections across food, water, energy and the environment are poorly understood and politically neglected. There is currently limited recognition of the urban nexus interconnections and their impact on fuel poverty and air pollution at city and national level policy in Sofia and Bulgaria, respectively.

Rather than discussing fuel poverty and vulnerability as a form of personal failure or inadequacy the proposed approach focuses on the creative and proactive ways in which households deal with fuel poverty using the urban nexus. It showcases the skills and tactics developed by many households, allowing for the more efficient and effective use of energy in the home and the alternative ways of mobilizing existing 
infrastructures and resources of their environment to cope with an issue which is more systemic than individual in nature (because of the high number of people affected by fuel poverty in Sofia and the long period of time this has taken place). Rather than trying to bring everyone up to equitable and often higher levels of energy use, the approach aims to highlight the ways in which people try to operate with the means they have available, and in ways that are shaped by forces outside of their immediate control. A nexus approach can thus create a wider space for informal and shared networking, across siloes of public and private, individual and communal, and systems of provisioning.

Failure to recognize the deep-routed and complex linkages between fuel poverty and air pollution in Sofia, could also jeopardise shifting towards a more inclusive energy transition, one which does not leave vulnerable customers behind and lock them into a social stigma of being seen as air polluters, as well as fuel poor. Above all, the nexus case of Sofia highlights the dangers of institutional blindness which comes from the segregation of issues into separate policy silos and departments, which treat fuel poverty separately from air pollution.

\section{References}

Alejos, E., \& Paz, M. (2013). An austerity-driven energy reform. Spanish Economic and Financial Outlook, 2, 51-60.

Allouche, J., Middleton, C., \& Gyawali, D. (2015). Technical veil, hidden politics: Interrogating the power linkages behind the nexus. Water Alternatives, 8, 610-626.

Al-Saidi, M., \& Elagib, A. (2017). Towards understanding the integrative approach of the water, energy and food nexus. Science of the Total Environment, 574, 1131-1139.

Boardman, B. (1991). Fuel poverty: From cold homes to affordable warmth. Belhaven.

Boardman, B. (1993). Opportunities and constraints posed by fuel poverty on policies to reduce the greenhouse effect in Britain. Applied Energy, 44, 185-195.

Boardman, B. (2010). Fixing fuel poverty: Challenges and solutions. Earthscan.

Boardman, B. (2012). Fuel poverty. International Encyclopedia of Housing and Home, 221-225.

Bouzarovski, S. (2014). Energy poverty in the European Union: Landscapes of vulnerability. Wiley Interdisciplinary Reviews: Energy and Environment, 3(3), 276-289.

Bouzarovski, S., Sarlamanov, R., \& Petrova, S. (2011). The governance of energy poverty in Southeastern Europe. The Institut français des relations internationals.

Bradshaw, J., \& Hutton, S. (1983). Social policy options and fuel poverty. Journal of Economic Psychology, 3, 249-266.

Buzar, S. (2007). Energy poverty in Eastern Europe: Hidden geographies of deprivation. Ashgate.

Cairns, R., \& Krzywoszynska, A. (2016). Anatomy of a buzzword: The emergence of the 'waterenergy-food' nexus in UK natural resource debates. Environmental Science \& Policy, 64, 164-170.

Carper, M., \& Staddon, C. (2009). Alternating currents: EU expansion, Bulgarian capitulation and disruptions in the electricity sector of South-east Europe. Journal of Balkan and Near Eastern Studies, 11(2),179-195

Daher, B., Mohtar, R. H., Lee, H., \& Assi, A. (2017). Modeling the water-energy-food nexus. In P. Abdul Salam, S. Shrestha, V. Prasad Pandey, \& A. K. Anal (Eds.), Water-energy-food nexus: Principles and practices. (pp. 55-66). Wiley. 
de Grenade, R., House-Peters, L., Scott, C. A., Thapa, B., Mills-Novoa, M., Gerlak, A., et al. (2016). The nexus: Reconsidering environmental security and adaptive capacity. Current Opinion in Environmental Sustainability, 21, 15-21.

De Laurentiis, V., Hunt, D. V. L., \& Rogers, C. D. F. (2016). Overcoming food security challenges within an energy/water/food nexus (EWFN) approach. Sustainability, 8, 95.

de Loe, R. C., \& Patterson, J. J. (2017). Rethinking water governance: Moving beyond water-centric perspectives in a connected and changing world. Natural Resources Journal, 57, 75-99.

EPOV (EU Energy Poverty Observatory). (2020). Member state report: Bulgaria. https://www.ene rgypoverty.eu/sites/default/files/downloads/observatory-documents/20-06/extended_member_ state_report_-_bulgaria.pdf

Eurostat. (2020). Inability to keep home adequately warm-EU-SILC survey. https://appsso.eur ostat.ec.europa.eu/nui/show.do?lang=en\&dataset=ilc_mdes01

Hajdinjak, M., \& Asenova, D. (2019). Sustainable energy consumption and energy poverty: Challenges and trends in Bulgaria. In F. Fahy, G. Goggins, \& C. Jensen (Eds.), Energy demand challenges in Europe. Cham.

HEAL. (2018). Air pollution and health in Bulgaria facts, figures and recommendations. Briefing. Air Quality. https://www.env-health.org/wp-content/uploads/2018/11/HEAL-Brief-Pos_AIR_ Bulgaria.pdf

Hiteva, R. (2017). Affordability and unevenness in provisioning of water and energy in Sofia. Resnexus blog. https://resnexus.org/blog/affordability-unevenness-provisioning-water-energysofia/

Howden-Chapman, P., Viggers, H., Chapman, R., O'Sullivan, K., Telfar, L. B., \& Lloyd, B. (2012). Tackling cold housing and fuel poverty in New Zealand: A review of policies, research, and health impacts. Energy Policy, 49, 134-142.

InventAir. (2018). InventAir: Report on the energy poverty and air quality status in the Eastern European Countries. https://www.inventair-project.eu/images/IA-Status-report.pdf

Jupp, E. (2016). Families, policy and place in times of austerity. Area, 49(3), 266-272.

Kaika, M. (2012). The economic crisis seen from the everyday. City, 16(4), 422-430.

Katsoulakos, N. (2011). Combating energy poverty in mountainous areas through energy-saving interventions. Mountain Research and Development, 31, 284-292.

Kisyov, P. (2014). Report on national situation in the field of energy poverty-Bulgaria. REACH https://reach-energy.eu/wordpress/wp-content/uploads/2014/12/D2.2-EAP_EN.pdf

Knight, D. M. (2014). A critical perspective on economy, modernity and temporality in contemporary Greece through the prism of energy practice. London School of Economics and Political Science, London.

Kulinska, E. (2017). Defining energy poverty in implementing energy efficiency policy in Bulgaria. Economic Alternatives, 4, 671-684.

Lenz, N. V., \& Grgurev, I. (2017). Assessment of energy poverty in New European Union member states: The case of Bulgaria, Croatia and Romania. International Journal of Energy Economics and Policy, 7(2), 1-8.

Liddell, C., Morris, C., McKenzie, S. J. P., \& Rae, G. (2012). Measuring and monitoring fuel poverty in the UK: National and regional perspectives. Energy Policy, 49, 27-32.

Miralles-Wilhelm, F. (2016). Development and application of integrative modeling tools in support of food-energy-water nexus planning-A research agenda. Journal of Environmental Sciences, $6,3-10$

Moore, R. (2012). Definitions of fuel poverty: Implications for policy. Energy Policy, 49, 19-26.

O’Brien, M. (2011). Policy summary: Fuel poverty in England. Lancet.

Pahl-Wostl, C. (2017). Governance of the water-energy-food security nexus: A multi-level coordination challenge. Environmental Science \& Policy, 92, 356-367.

Petrova, S., \& Prodromidou, A. (2019). Everyday politics of austerity: Infrastructure and vulnerability in times of crisis. EPC: Politics and Space, 37(8), 1380-1399. 
Petrova, S., Gentile, M., Mäkinen, I. H., \& Bouzarovski, S. (2013). Perceptions of thermal comfort and housing quality: exploring the microgeographies of energy poverty in Stakhanov, Ukraine. Environment and Planning, A45, 1240-1257.

Prasad, G., Stone, A., Hughes, A., \& Stewart, T. (2012). Towards the development of an energywater-food security nexus based modelling framework as a policy and planning tool for South Africa. Presented at Strategies to Overcome Poverty and Inequality Conference, University of Cape Town, Cape Town.

Rasul, G., \& Sharma, B. (2015). The nexus approach to water-energy-food security: An option for adaptation to climate change. Climate Policy, 16, 682-702.

Roy, A. (2005). Urban informality: Toward an epistemology of planning. Journal of the American Planning Association, 71(2), 147-158.

Saffari, A., Daher, N., Samara, C., et al. (2013). Increased biomass burning due to the economic crisis in Greece and its adverse impact on wintertime air quality in Thessaloniki. Environmental Science \& Technology, 47(23), 13313-13320.

Santamouris, M., Alevizos, S. M., Aslanoglou, L., et al. (2014). Freezing the poor-Indoor environmental quality in low and very low income households during the winter period in Athens. Energy and Buildings, 70, 61-70.

Simpson, G. B., \& Jewitt, P. W. G. (2019). The development of the water-energy-food nexus as a framework for achieving resource security: A review article. Frontiers in Environmental Science, $7,1-8$.

Tirado Herrero, S., \& Urge-Vorsatz, D. (2012). Trapped in the heat: A post-communist type of fuel poverty. Energy Policy, 49, 60-68.

Valentine, G. (2008). The ties that bind: Towards geographies of intimacy. Geography Compass, 2(6), 2097-2110.

Walker, G. (2014). The dynamics of energy demand: Change, rhythm and synchronicity. Energy Research \& Social Science, 1, 49-55.

Wichelns, D. (2017). The water-energy-food nexus: Is the increasing attention warranted, from either a research or policy perspective? Environmental Science \& Policy, 69, 113-123.

Williams, J., Bouzarovski, S., \& Swyngedouw, E. (2018). The urban resource nexus: On the politics of relationality, water-energy infrastructure and the fallacy of integration. Environment and Planning C: Politics and Space, 37(4), 652-669.

Open Access This chapter is licensed under the terms of the Creative Commons Attribution 4.0 International License (http://creativecommons.org/licenses/by/4.0/), which permits use, sharing, adaptation, distribution and reproduction in any medium or format, as long as you give appropriate credit to the original author(s) and the source, provide a link to the Creative Commons license and indicate if changes were made.

The images or other third party material in this chapter are included in the chapter's Creative Commons license, unless indicated otherwise in a credit line to the material. If material is not included in the chapter's Creative Commons license and your intended use is not permitted by statutory regulation or exceeds the permitted use, you will need to obtain permission directly from the copyright holder.

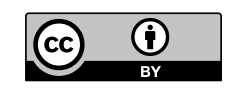

